\title{
Head and Neck Cancer Burden in India
}

\section{Manik Rao Kulkarni}

\begin{abstract}
Introduction: Head and neck cancer in India has distinct demographic profile, risks factors, food habits, and personal and family history. They are emerging as major public health problems in India, which are lifestyle related, have a lengthy latent period and need dedicated infrastructure and human resource for treatment. Need based and coordinated research for understanding the threats to the nation from chronic diseases such as head and neck cancers and ways to defy such threats will assume increasing importance.
\end{abstract}

Magnitude of problem in India: Overall, $57.5 \%$ of global head and neck cancers occur in Asia especially in India. Head and neck cancers in India accounted for $30 \%$ of all cancers. In India, 60 to $80 \%$ of patients present with advanced disease as compared to $40 \%$ in developed countries. A slow decline in the incidence of most of head and neck cancers has been documented in India.

Management of head and neck cancers in India: The problem of managing head and neck cancers in India is somewhat different, as compared to the west. The major shortcoming is to cope up, with the loss to follow-up, which makes the task of conducting and reporting the end results of clinical trials awfully difficult.

Conclusion: The highest priority for cancer control should be given to the burden of head and neck cancer in India. The emphasis should be on preventing the onset and detecting the disease at an early stage. In developing countries like India, implementing cancer control activities has to be prioritized, making optimal use of limited resources to deliver the utmost benefit to the largest number of people.

Keywords: Head and neck cancer, Incidence, Etiology, Management, Tobacco, Oral cancer, Radiotherapy, Burden.

How to cite this article: Kulkarni MR. Head and Neck Cancer Burden in India. Int J Head and Neck Surg 2013;4(1):29-35.

\section{Source of support: Nil}

\section{Conflict of interest: None}

\section{INTRODUCTION}

Head and neck cancers in India are emerging as major public health problems, which are lifestyle related, have a lengthy latent period and need dedicated infrastructure and human resource for treatment. In India, 6.5\% of the total population is represented by older persons (60 years and above). ${ }^{1}$ The burden of cancer in India is on the rise with the control of infectious diseases and increased longevity of the growing population.

Head and neck cancer in India has distinct demographic profile, risks factors, food habits, family and personal history. ${ }^{2}$ The head and neck region constitute several delicate, intricately organized structures vital for basic physiological needs, and crucial for appearance, expression, and social interaction. Head and neck cancers can cause varying degrees of structural deformities, and functional handicaps, depending on the site, size, and patterns of spread, thereby compromising well-being and self-esteem. The quality of life can be further worsened by treatment of head and neck tumors which can induce additional mutilation. $^{3}$

In our surge toward becoming a healthier, wealthier and finest nation, need based and coordinated research for understanding the threats to the nation from chronic diseases such as head and neck cancers and ways to defy such threats will assume increasing importance. ${ }^{4}$

Magnitude of problem in India: Overall, 57.5\% of global head and neck cancers (excluding esophageal cancers) occur in Asia especially in India, for both sexes. ${ }^{5}$

Head and neck cancers in India accounted for 30\% of all cancers in males (Fig. 1) except Dibrugarh in Assam (49.6\%). In females they constitute 11 to $16 \%$ of all sites of cancers (Fig. 2). Among them, tongue and mouth in males contribute to more than one-third of the total cancers except in Dibrugarh where hypopharynx (34.5\%) was the major contributor and among females mouth cancer was the leading cause (Fig. 3). ${ }^{6}$

Over 200,000 cases of head and neck cancers occur each year in India. Nearly 80,000 oral cancers are diagnosed every year in our country. ${ }^{7}$ Nearly two-thirds of oral cancers are located in the buccogingival sulcus, where the betel quid is kept for long periods in the oral cavity. The location and etiology of this buccogingival cancer may warrant the term 'the Indian oral cancer'. Maximum number of mouth cancers

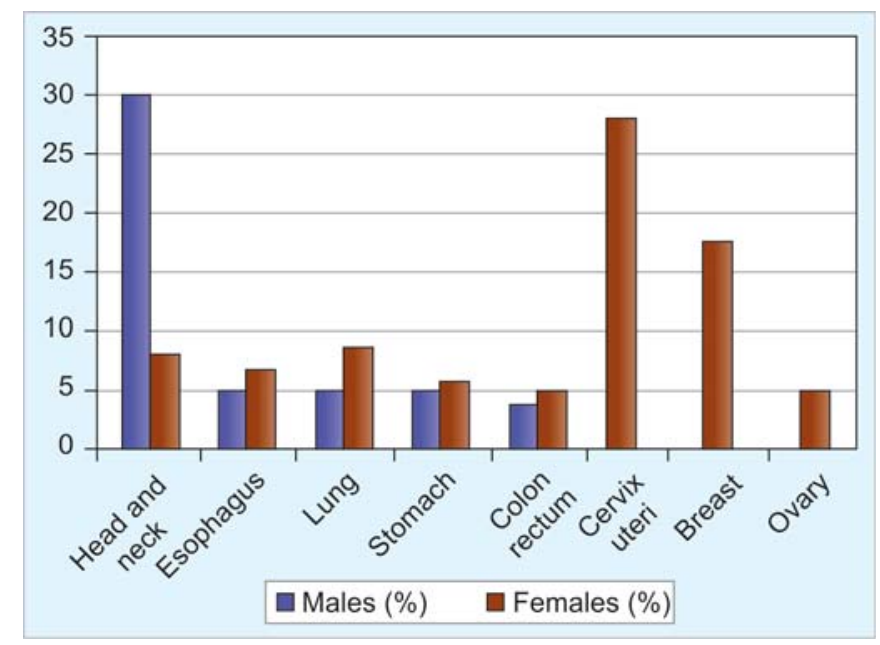

Fig. 1: Top cancers in India in both sexes ${ }^{8,25}$ 
among males was seen after the age of 55 years except in Mumbai where it is more common in the age group of 45 to 49 years, whereas there is much variation seen in females. ${ }^{8}$

Around 40,000 cases of pharyngeal cancers excluding nasopharyngeal cancers (31\% of global cases) and nearly 29,000 cases of laryngeal cancers (18\% of global cases) occur in India every year. India stands second place in prevalence of esophageal cancers $(77,000)$, after china. ${ }^{5}$

Regional differences in the prevalence of risk factors are the reason behind the variability in incidence and pattern of head and neck cancer. Most of the oral lesions are detected in their advanced stages although oral cavity is accessible for visual examination. In fact, 60 to $80 \%$ of patients present with advanced disease in India, as compared to $40 \%$ in developed countries, consistent with which, the overall survival is also reduced. ${ }^{9}$

In an other study at Kidwai Memorial Institute of Oncology, in Bengaluru, 2004-2005, pharyngeal cancers

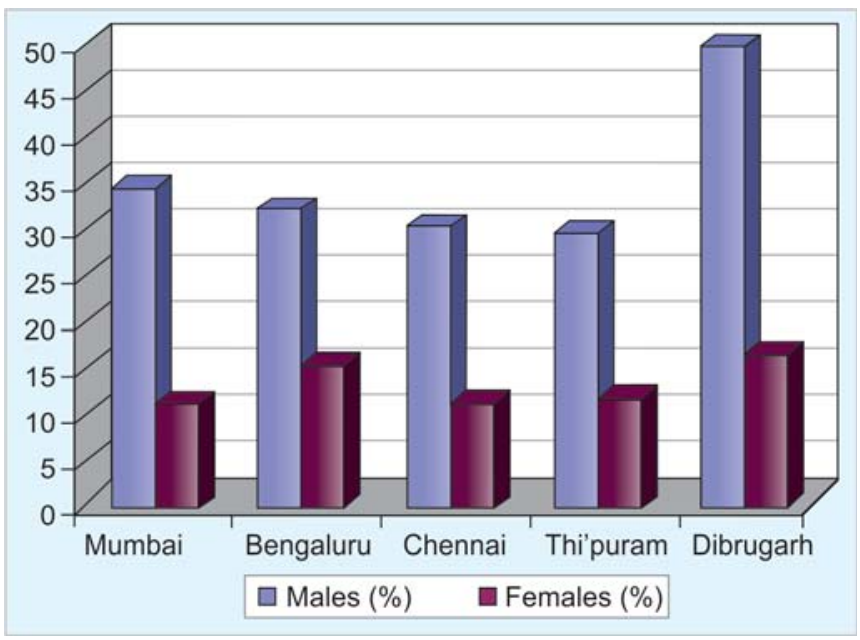

Fig. 2: Proportion (\%) of head and neck cancers relative to all sites, across various regions in India (2004-2006) $)^{8}$

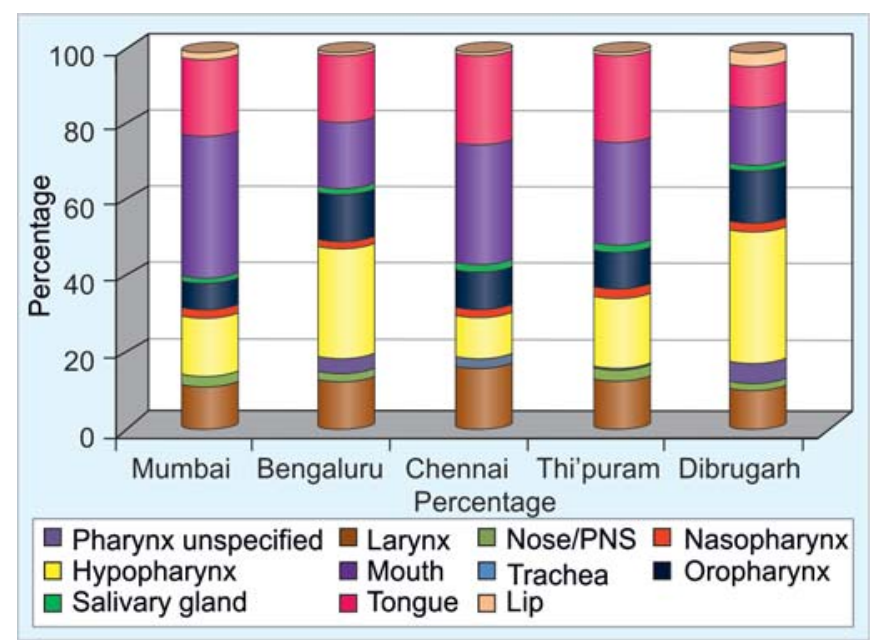

Fig. 3: Stack diagram (100\%) showing proportion of each head and neck cancer sites relative to all head and neck cancers in males, in various regions in India (2004-2006) ${ }^{8}$ was the leading sites of cancer in males (14.1\%), especially hypopharynx (Fig. 4) and then oral cavity (11.2\%). In females, next to cancer cervix and breast, cancers of oral cavity (11\%), and esophagus remained most common cancers. ${ }^{10}$

\section{INCIDENCE}

Bhopal has the worlds highest age standardized incidence of both tongue (10.9) and mouth cancers (9.6) in males. Trivandrum has a high incidence of oropharyngeal cancers in males.

The world's highest incidence of cancers associated with tobacco are found in districts of northeast, central and southern India. The world's highest incidence of cancers in men of the lower pharynx (11.5 per 100,000 people) and tongue (7.6 per 100,000 people) ${ }^{6}$ are reported in Aizawl district of northeastern India. One of the highest incidence rates of mouth cancer among men is found in Pondicherry (8.9 per 100,000) (Fig. 5).

A 'belt of thyroid' cancer has been identified in women in coastal districts of Goa, Karnataka and Kerala. Site specific age adjusted incidence rates for oropharynx and hypopharynx are highest in kamrup (Fig. 6).

In pediatric age group incidence of head and neck tumors is quite rare $(0.25 \%)$, with the ratio of $1.8: 1$ in males and females. ${ }^{22}$ Five percent of all cancers in children are head and neck malignancies. Most commonly found are the lymphomas (43.39\%) followed by the rhabdomyosarcoma (20.75\%). The malignant lesions were largely seen above 5 years of age (69.81\%), maximum occurring in the age group of 10 to 12 years (47.17\%). ${ }^{11}$

\section{TIME TRENDS IN CANCER RATES IN INDIA}

A slow decline in the incidence of most of the head and neck cancers has been documented in India (Table 1). It is

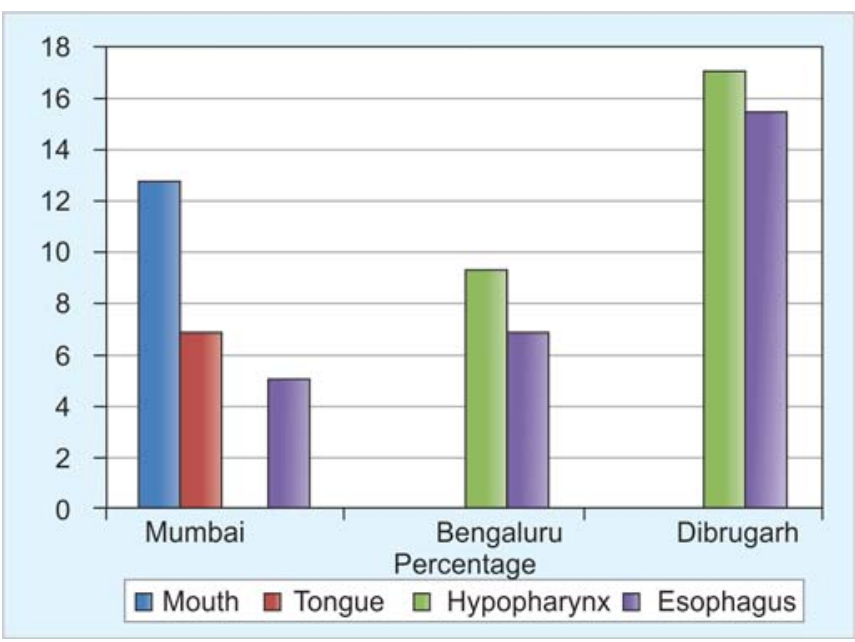

Fig. 4: The proportion of given sites of cancer, based on recent HBCR (2004-2006) $)^{8}$ 


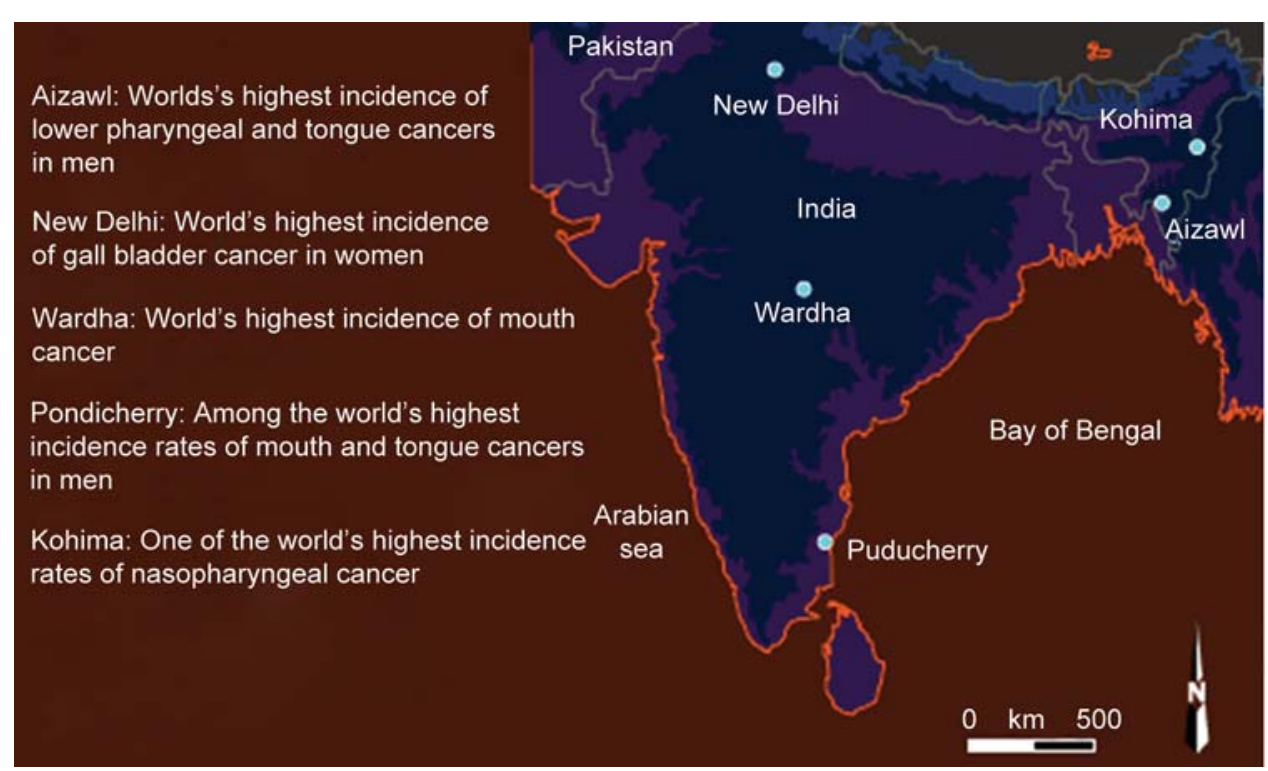

Fig. 5: Incidence of various cancers in some cities in India ${ }^{24}$

observed that trends in tongue, hypopharynx and larynx are declining in almost all the population-based registries while cancer of mouth is either on the rise or stable. ${ }^{12}$ Oral cancers overall has decreased gradually for males since 1986, but has been stable for females. In both sexes less than 40 years, the incidence of oral cancers has been stable since $1986 .{ }^{5}$

The overall annual incidence of cancer in children under 15 years of age raised from 11.22 to 14.03 cases/100,000 person-years in 1994 to 1996, an increase of 25\%. In the time period of 1973 to 1975 an even greater increase in the incidence of pediatric head and neck malignancies has been noted. ${ }^{11}$

\section{ETIOLOGY IN INDIA}

Most head and neck cancer cases and deaths are due to both individual predisposition linked to certain genetic characteristics, and exposure to carcinogens caused by lifestyle behaviors. In addition, exposure to two or more of following risk factors has a synergistic effect in increasing oral cancer risk. ${ }^{13}$

- Tobacco smoking in the form of cigarettes, bidis, cigars/ chutta/cheroot, dhumti (Goa), the water pipes/hookah (north India), reverse chutta smoking (in coastal regions of Andhra Pradesh and Orissa), hookli (Gujarat) and chillum (northeastern parts of India). Around 57\% of all men and $11 \%$ of women in India, between 15 and 49 years of age use some form of tobacco. Results from the global youth tobacco survey in India show that about 10 to $20 \%$ of students in 8 th to 10 th grades (about 1315 years), currently use tobacco in some form.

The strong association of cancers of the pharynx and oral cavity with the tobacco use is well recognized. Epidemiological studies show that the risk of developing oral cancer is five to nine times greater for smokers than for nonsmokers. This risk may multiply to as much as seventeen times greater for exceedingly heavy smokers of 80 or more cigarettes per day. About one-fourth of oral cancer cases are attributable to cigarette smoking. More than 60 carcinogens are present in cigarette smoke and at least 16 in smokeless tobacco have been identified. ${ }^{14}$

- Besides smoking, use of smokeless tobacco is extremely prevalent. The use of betel quid (pan) is extremely

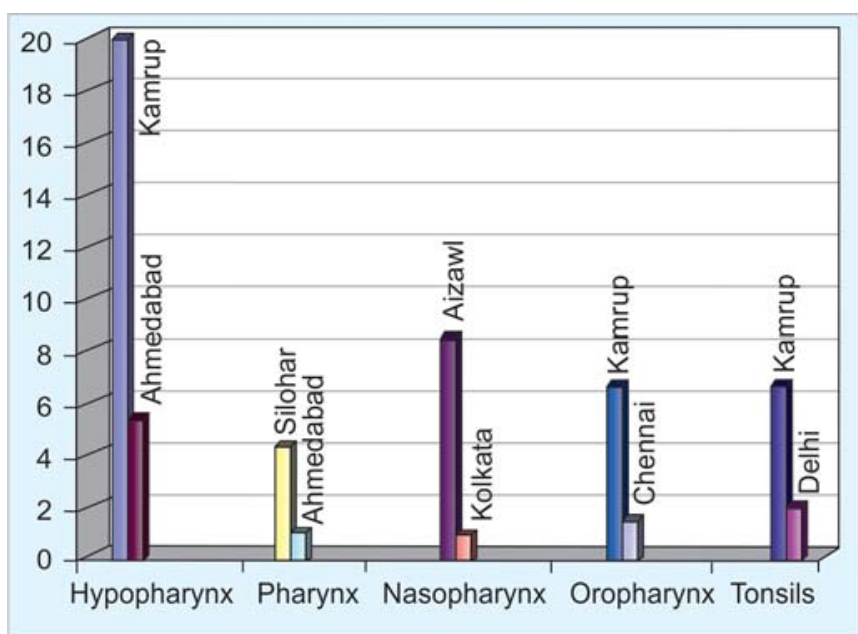

Fig. 6: Site-specific age-adjusted incidence rates $^{6}$

Table 1: Decline in age-adjusted incidence rates in males from 1966 to $1997^{5}$

\begin{tabular}{lcl}
\hline Cancer site & $\begin{array}{c}\text { Change in age-adjusted } \\
\text { incidence rates (\%) }\end{array}$ & Change (\%) \\
\hline Tongue & $14-5.7$ & 59.3 decrease \\
Oropharynx & $6.1-0.8$ & 87 decrease \\
Larynx & $13.8-7$ & 49 decrease \\
Mouth & $7.5-5.7$ & 24 decrease \\
Hypopharynx & $10-5.9$ & 41 decrease \\
\hline
\end{tabular}


widespread in many parts of India. In addition, zarda, gutka, kharra, mawa, and khainni are custom mixed by vendors and are all dry mixtures of areca nut flakes, lime, tobacco power. ${ }^{9}$ It is also used as a moist snuff containing lime with tobacco, vegetable oil and water (Naswar/Nass) and also in the form of dried tobacco applied on gums and teeth. ${ }^{5}$

Betel quid chewing, well known to cause precancerous conditions of the mouth like submucosal fibrosis has been identified as an oral carcinogen in humans, with evidence for a dose-response relationship, by the International Agency for Research on Cancer. ${ }^{15}$

A recent Population Based Cancer Registry (PBCR) report shows that the proportion of cancers related to tobacco use among males in India, varies from 33.4\% in Bangalore to 50.6 in Ahmedabad. The relative proportion of tobacco cancers, varies from 15.2 in both Bangalore and Chennai to 10.7 in Delhi among females. ${ }^{9}$ Head and neck cancer risk markedly increases when smoking duration is more than twenty years and the daily frequency of smoked cigarettes is higher than twenty. ${ }^{16,17}$

- Alcohol consumption regularly, is associated with an increased risk for oral cancer, which is dose-dependent. Regular consumption of 4 to 5 drinks daily, the risk for oral cavity cancer is 2- to 3-fold higher than among nondrinkers. Overall, 7 to $19 \%$ oral cavity cancer cases are attributable to heavy alcohol drinking. ${ }^{18}$

- Alcohol alone and in combinations with smoking: The addition of alcoholic drink, to intake of tobacco in any form further increases the risk for oral cancer by eleven fold. ${ }^{18}$ A case control study on oral cancer (buccal and labial mucosa) in Thiruvananthapuram, showed that alcohol alone conferred a nonsignificant odds ratio of 2.6, however there was a significant odds ratio seen with alcohol with bidi smoking (8.5), alcohol and pan tobacco chewing (20), and with alcohol, pan and smoking altogether (31.4\%). ${ }^{5}$

- Recent evidence suggests that human papilloma virus (HPV) may be linked with some oropharyngeal and oral cancers. HPV-16 has been detected in up to $22 \%$ and HPV-18 has been found in up to $14 \%$ of oral cancers cases.

Sexual behaviors are linked with cancer risk at the head and neck cancer sites that have previously been associated with HPV infection. Having a history of six or more lifetime sexual partners and four or more lifetime oral sex partners has been linked with cancer of the oropharynx. $^{19}$

- Oral cavity lichen planus, in specific the erosive form, may be associated with an enhanced cancer risk. Iron deficiency anemia in combination with dysphagia and postcricoid webs (Plummer-Vinson syndrome) is associated with a high risk for development of carcinoma of the oral cavity, oropharynx and esophagus. ${ }^{15,20}$

- Nutrition and cancers: Regular vegetable consumption and fish in the diet have been shown to be protective, in a case control study in India on various head and neck cancers, with nonconsumers having 2-fold risks. To a lesser extent butter milk and pulses were also found to be protective.

- Oral precancerous conditions: In India majority of oral cavity cancers are preceded by precancerous lesions, which have similar etiology to oral cavity cancers and are almost solely found in tobacco users. There are three major types of lesions. The commonest form being leukoplakia (Indian prevalence 0.2-5.2\%) with malignant transformation rates 0.13 to $10 \%$. Erythroplakias are the most severe of all the precancerous lesions and carry a much higher risk of malignancy transformation than leukoplakia. The other precancerous lesion being submucosal fibrosis with malignant transformation of about $17 \%$ and is considered as important factor in the increasing incidence of oral cancers in individuals 35 years and below in India. ${ }^{5}$

- Chronic actinic exposure is associated with the occurrence of carcinomas of the lip vermilion.

- Immunosuppression appears to predispose some individuals to an enhanced risk for oral cancers. In a number of patients who have undergone kidney transplantation and receiving immunosuppressive medications, cancers of the lip have been reported. Similarly in some of the young AIDS patients oral carcinomas have even been documented. ${ }^{14}$

\section{MANAGEMENT OF HEAD AND NECK CANCERS IN INDIA}

The problem of managing head and neck cancers in India is somewhat different, as compared to the West. The major shortcoming is to cope up, with the loss to follow-up, which makes the task of conducting and reporting the end results of clinical trials awfully difficult.

Based on the Hospital Based Cancer Registries (HBCR) report 2004 to 2006, in both sexes, microscopic examination was the most widely used method of diagnosis for the head and neck cancers. Over $80 \%$ of cancers in both sexes had regional spread of disease at the time of diagnosis except in Mumbai where 77.8 and $72.4 \%$ in males and females respectively had regional spread.

Diagnostic infrastructure in many parts of India is scarce. The services of a pathologist or pathology/cytology center which are crucial for diagnosing cancer are not available in many districts in India. There is a significant urban concentration of facilities because of economic and 
geographic constraints and lack of man power. A significant number of cancers diagnosed in the population are not treated.

Treatment facilities are also mostly restricted to urban areas of the country. There are no uniform protocols for management, the affordability and availability of cancer treatment shows broad disparities. Radiotherapy is the most common modality of treatment for head and neck cancers in various prominent cities in India (Fig. 7). Surgery with radiotherapy being the most common form of treatment given in Mumbai (36.9\% cases) (Table 2) .

Treatment results are about $20 \%$ less than what is observed for similar conditions in more developed countries, mostly due to late diagnosis and inappropriate treatment. Childhood cancers are highly curable but this has not been achieved in India due to lack of access to quality care and lack of support systems. ${ }^{21}$ The highest 5 years age standardized relative survival for tongue, hypopharnx, laryngeal cancer was seen in Mumbai (Table 3).

The head and neck cancers prognosis has not experienced a considerable enhancement, despite the advancements and great strides that have been made in recent decades. Since 5-year survival is directly related to stage at diagnosis, the need is for early diagnosis, which depends upon a wise clinician or patient who may identify a suspicious symptom or lesion, while it is still at an early

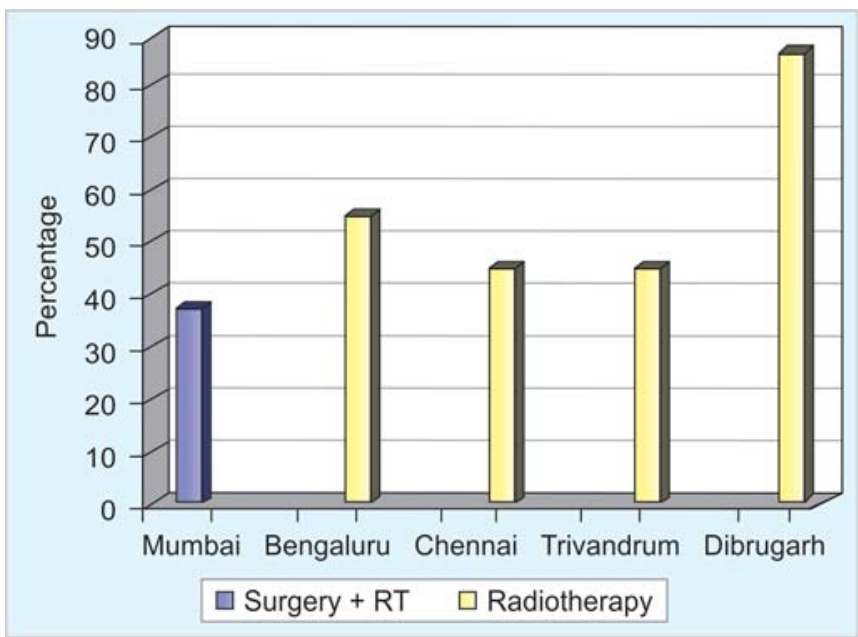

Fig. 7: Most common modality of treatment given for head and neck cancers in various prominent cities in India ${ }^{8}$ stage. ${ }^{14}$ Mortality in India due to head and neck cancers is at least half of the incidence, basically due to late presentation of patients for treatment ${ }^{5}$ (advanced stage III $=39 \%$, IV $=23 \%)^{2}{ }^{2}$

In India, the high incidence of head and neck cancers is further compounded by the fact that there are only about 200 trained head and neck oncologists, the bulk of them in the six major cities. As a result, a large number of patients are referred for primary radiation therapy, irrespective of stage and probability of disease control. The bulk of the cancer load is managed by a dozen regional cancer centers, which are government funded, overburdened with patients, have a long waiting lists and no specialized head and neck divisions. The concept of health insurance in India is not widely established and affordability is a major problem in India. ${ }^{7}$

Population based 5-year survival for patients with the group of oral cavity cancers is approximately $50 \%$ in the United States, ranges from 45 to $49 \%$ in Europe and approximately 30\% in India (Fig. 8). There has been very little progress in overall 5-year survival over the last 3 decades; although 5-year survival for localized cancers exceeded $80 \%$ in the United States, it was approximately $60 \%$ in selected developing countries. The overall survival which is poor reflects the advanced stage at diagnosis for the vast majority of these cancers, as 5-year survival seldom exceeds $40 \%$ for patients with regional disease and $15 \%$ for those who have disease with distant metastasis. ${ }^{22}$

Although illiteracy and poverty are the often cited reasons for our neglect toward extent of quality of life in head and neck cancer patients, it is actually the lack of physician awareness, and the nonavailability of valid tools that are responsible for the paucity of quality of life studies in India. ${ }^{3}$

Based on the survival studies from Mumbai in year 2000, less than $25 \%$ of cancers were localized in the organ of origin at diagnosis and depending on the subsite, the 5-year survival for localized cancers ranged from 53 to $80 \%$. Those with regional spread of disease, experienced a 3-fold increased risk of death, and those with distant metastasis experienced a 6-fold excess risk. ${ }^{12}$

Table 2: Relative proportion of head and neck cancer patients according to the type of treatment given in males 2004-2006 (consolidated report of the HBCRs: 2004-2006) ${ }^{8}$

\begin{tabular}{lccccc}
\hline Type of treatment & Mumbai & Bengaluru & Chennai & Trivandrum & Dibrugarh \\
\hline Surgery & $19.7 \%$ & $11 \%$ & $4.2 \%$ & $7.2 \%$ & $3.3 \%$ \\
Radiotherapy & 18.8 & 54.8 & 44.7 & 44.6 & 85.9 \\
Chemotherapy & 6.1 & 5.2 & 1.2 & 5.4 & 2.3 \\
Surgery + radiotherapy & 36.9 & 16 & 17.9 & 9.9 & 4.4 \\
Surgery + chemotherapy & 0.8 & 0.8 & 0 & 0.8 & 0.2 \\
Radiotherapy + chemotherapy & 15.5 & 10.6 & 28.2 & 26.2 & 3.4 \\
All three modalities & 2.2 & 0.2 & 3.9 & 5.5 & 0.6 \\
\hline
\end{tabular}




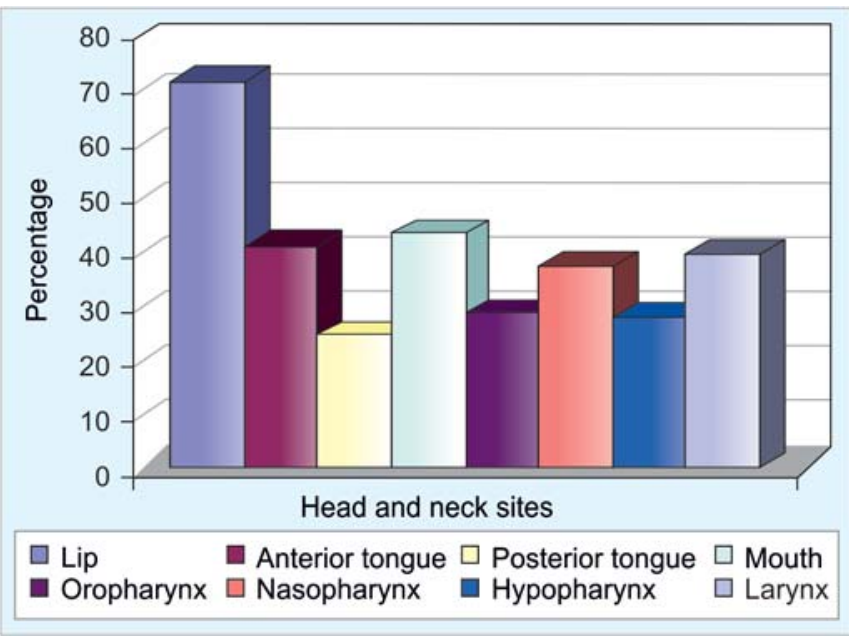

Fig. 8: Five-year relative survival rates of head and neck cancers in Mumbai in $2002^{23}$

\section{HEAD AND NECK CANCER CONTROL IN INDIA: INTERVENTIONS BY PRIMARY PREVENTION}

- The most effective prevention strategy is reduction in consumption of tobacco in all forms. These cancers can be prevented to a large extent through a comprehensive tobacco control program which includes education, awareness, legislation, community participation and tobacco cessation services especially targeted at teenage students who pick up habit at an early time.

- A proportion of cancers are considered to be related to the dietary practices. The role of diet takes special importance in countries like India, which are fast surging toward industrialization and westernization. Timely action has to be taken to spread the significance of a healthy diet rich in vegetables and fruits. A recent study shows that consumption of vegetables, iron, zinc, copper, ascorbic acids, beta carotene are associated with decreased risk of precancerous conditions. ${ }^{5}$ More attention has been given recently, on particular aspects of the Indian diet, such as vegetarian diet, additives in food and spices. The role of turmeric (Curcuma longa), a common constituent in Indian cuisines, has received specific interest for cancer prevention. Researchers have also investigated cumin seeds, chilies, herbal health foods, and a variety of plant seeds for their apparent cancer preventive properties. ${ }^{23}$

For prevention of cancers related to infectious agents such as HPV and hepatitis B virus, vaccination strategies have to be efficiently utilized.

Mass examinations (screenings): Early detection should therefore be an important strategy-through the two principal routes of public education and screening. As oral cancer has well-defined risk factors, these may be modified giving real hope for primary prevention. The most widely used screening test for oral cancer is visual inspection of the oral cavity. ${ }^{10}$ The test performance is acceptable in terms of specificity, sensitivity and predictive value and, hence, a suitable screening test for oral cancer. ${ }^{11,22}$

Need of the hour: A multidisciplinary approach to cancer treatment is necessary and this has to be made available at all Regional Cancer Centers, district hospitals and tertiary care centers. The services of a trained surgeon and a clinical oncologist are required to plan the most apt treatment. Radiotherapy services are still the mainstay of treatment given to the major proportion of advanced head and neck cancers in India. Optimal strategies have to be identified and implemented, given the long waiting lists of patients and the distance they have to travel to reach treatment facilities. Patients for palliative treatment and curative treatment need to be identified at the beginning of the treatment plan. An essential list of drugs has to be prepared for cancer chemotherapy and the chemotherapy facilities have to be made available in all treatment centers. Rehabilitation and availability of prosthetics are to be made accessible at lower costs.

\section{HUMAN RESOURCE GENERATION}

A large number of trained personnel in various specialties are required for control of cancer. These include epidemiologist, cytotechnologists, cytotechnicians and nurses trained in palliative care and in care of patients on chemotherapy and radiotherapy, medical personnel in all

Table 3: Comparison of 5-year age standardized relative survival of major head and neck cancer sites between various registries ${ }^{23}$

\begin{tabular}{|c|c|c|c|c|c|}
\hline \multirow[t]{2}{*}{ Cancer site } & \multicolumn{5}{|c|}{ Five-year age standardized relative survival (0-74 years) (\%) } \\
\hline & $\begin{array}{l}\text { Barshi } \\
1993-00\end{array}$ & $\begin{array}{l}\text { Bhopal } \\
\text { 1991-95 }\end{array}$ & $\begin{array}{l}\text { Chennai } \\
1990-99\end{array}$ & $\begin{array}{c}\text { Karunagappally } \\
\text { 1991-97 }\end{array}$ & $\begin{array}{l}\text { Mumbai } \\
1992-99\end{array}$ \\
\hline Tongue & 11.8 & 13.1 & 23.4 & 29.6 & 29.7 \\
\hline Oral cavity & 26.1 & 37.5 & 36.7 & 45.3 & 36.0 \\
\hline Tonsil & - & - & 15.6 & - & 16.6 \\
\hline Oropharynx & - & - & 20.7 & - & 20.4 \\
\hline Nasopharynx & - & - & - & - & 24.7 \\
\hline Hypopharynx & 10.0 & 2.0 & 15.0 & 15.5 & 23.1 \\
\hline Esophagus & 5.3 & 3.6 & 8.6 & 18.5 & 16.2 \\
\hline Larynx & 15.7 & 15.7 & - & 28.3 & 36.0 \\
\hline
\end{tabular}


aspects of cancer treatment, physiotherapists and occupational therapists, counselors and more importantly trained head and neck cancer surgeons.

\section{PALLIATIVE CARE}

Palliative care and pain relief are essential to impart good quality of life for the cancer patients. Oral morphine is the basis for management of cancer pain and this has to be made available at all centers.

\section{CONCLUSION}

The highest priority for cancer control should be given to the burden of head and neck cancer in India. With many head and neck cancers are difficult to manage, but being highly preventable, the emphasis, therefore, should be on preventing the onset and detecting the disease at an early stage. In developing countries like India, implementing cancer control activities has to be prioritized, making optimal use of limited resources to deliver the utmost benefit to the largest number of people.

\section{ACKNOWLEDGMENT}

I sincerely want to thank Dr Pankaj Chaturvedi, Associate Professor, Tata Memorial Hospital, Mumbai for his inspiration and guidance and also would like to thank Dr Guruprasad Bhatt for his timely help.

\section{REFERENCES}

1. Shah B, Kumar N, Menon GR, et al. Assessment of burden of non-communicable diseases: A project supported by WHO. Indian Council of Medical Research, Delhi, 2006.

2. Mishra A, Singh VP, Verma V. Environmental effects on head and neck cancer in India. J Clin Oncol 2009;27 (suppl; abstr e17059).

3. Chaukar DA, Das AK, Deshpande MS, Pai PS, et al. Quality of life of head and neck cancer patient: Validation of the European organization for research and treatment of cancer QLQ-C30 and European organization for research and treatment of cancer QLQ-HandN35 in Indian patients. Indian J Cancer 2005 OctDec;42(4):178-84.

4. Sarin R. Indian national cancer control programme: Setting sight on shifting targets. J Can Res Ther 2005;1:240-48.

5. Chaturvedi P. Head and neck surgery. J Can Res Ther 2009; $5: 143$.

6. National cancer registry programme (ICMR) (2008). Consolidated Report of Population Based Cancer Registries: 2004-2005. Bangalore, India, 2008. Available from: www.ncrpindia.org/ Report/PreliminaryPages_PBCR2004_2005.pdf.

7. Head and Neck Cancer in India. Available from: http:// www.veedaoncology.com/PDF-Document/Head-Neck\%20 Cancer\%20In\%20India.pdf. [Last accessed on: 2011 Dec 26].

8. National Cancer Registry Programme (ICMR) (2009). Consolidated report of HBCR: 2004-2006. Bangalore, India.

9. Kekatpure V, Kuriakose MA. Oral Cancer in India: Learning from different populations. National newsletter and website from
New York Presbyterian Hospital 2010;14. Available from: http: //www.nypcancerprevention.com/issue/14/cancer_prevention/ feature/india.shtml.

10. Department of epidemiology and biostatistics (HBCR). Kidwai Memorial Institute of Oncology. Available from: http:// kidwai.kar.nic.in/statistics.htm.

11. Sengupta S, Pal R, Saha S, et al. Spectrum of head and neck cancer in children. J Indian Assoc Pediatr Surg 2009;14:200-03.

12. Yeole BB, Sankaranarayanan R. Survival from head and neck cancer in Mumbai (Bombay), India. Cancer 2000;89:437-44.

13. Petti S. Lifestyle risk factors for oral cancer. Oral Oncol 2009; 45(4-5):340-50.

14. Neville BW, Day TA. Oral cancer and precancerous lesions. CA Cancer J Clin 2002;52:195-215.

15. Sankaranarayanan R, Black RJ, Swaminathan R, Parkin DM. An overview of cancer survival in developing countries. IARC Sci Publ 1998;145:135-73.

16. Hashibe M, Brennan P, Benhamou S, et al. Alcohol drinking in never users of tobacco, cigarette smoking in never drinkers, and the risk of head and neck cancer: Pooled analysis in the International head and neck cancer epidemiology consortium. J Natl Cancer Inst 2007;99(10):777-89.

17. Applebaum KM, Furniss CS, Zeka A, Posner MR, Smith JF, Bryan J, et al. Lack of association of alcohol and tobacco with HPV16-associated head and neck cancer. J Natl Cancer Inst 2007;99(23):1801-10.

18. Subapriya R, Thangavelu A, Mathavan B, et al. Assessment of risk factors for oral squamous cell carcinoma in Chidambaram, Southern India: A case-control study. Eur J Cancer Prev 2007 Jun;16(3):251-56.

19. Heck JE, Berthiller J, Vaccarella S, et al. Sexual behaviors and the risk of head and neck cancers: A pooled analysis in the International head and neck cancer epidemiology (INHANCE) consortium. Int J Epidemiol 2010 Feb;39(1):166-81.

20. Berrino F, Sant M, Verdecchia V, Capocaccia R, Hakulinen T, Estéve J. Survival of cancer patients in Europe: The EUROCARE Study. IARC Scientific Publication 1995;132.

21. Sankaranarayanan R, Mathew B, Jacob BJ, et al. Early Findings from a community-based, cluster-randomized controlled oral cancer screening trial in Kerala, India. The Trivandrum Oral Cancer Screening Study Group. Cancer 2000 Feb 1;88(3): 664-73.

22. Sinha R, Anderson DE, McDonald SS, Greenwald P. Cancer risk and diet in India. J Postgrad Med 2003;49:222-28.

23. Sankaranarayanan R, Swaminathan R, Jayant K, Brenner H. An overview of cancer survival in Africa, Asia, the Caribbean and Central America: The case for investment in cancer health services. IARC Sci Publ 2011;162:257-91.

24. Ganapati M. India has some of the highest cancer rates in the world. BMJ 2005 Jan;330(7485):215.

25. Head and Neck Cancer in India. Available from: http:// www.veedaoncology.com/PDF-Document/Head-Neck\%20 Cancer\%20In\%20India. Last accessed on 2011 Dec 26.

\section{ABOUT THE AUTHOR}

\section{Manik Rao Kulkarni}

Assistant Professor, Department of ENT and Head and Neck Surgery Vijayanagar Institute of Medical Sciences, Bellary, Karnataka, India e-mail: drmanvrk@rediffmail.com 